\title{
Sonographic findings in bacterial meningitis in neonates and young infants
}

\author{
Ali Yikilmaz • George A. Taylor
}

Received: 28 February 2007 /Revised: 3 May 2007 / Accepted: 16 May 2007 / Published online: 5 July 2007

(C) Springer-Verlag 2007

\begin{abstract}
Cranial sonography plays an important role in the initial evaluation of infants with suspected bacterial meningitis and in monitoring for complications of the disease. Echogenic widening of the brain sulci, meningeal thickening and hyperemia suggest the diagnosis in an atrisk population. Sonography can identify the presence of extra-axial fluid collections, and color Doppler sonography can be very helpful in differentiating benign enlargement of subarachnoid spaces from subdural effusions. Intraventricular debris and stranding, and an irregular and echogenic ependyma are highly suggestive findings associated with ventriculitis. Sonography can play an important role in the detection of postinfectious hydrocephalus, in the determination of the level of obstruction, and in the evaluation of intracranial compliance. Focal or diffuse parenchymal involvement can represent parenchymal involvement by cerebritis, infarction, secondary hemorrhage or early abscess.
\end{abstract}

Keywords Meningitis · Ultrasonography · Doppler · Bacterial infections . Central nervous system infections . Children

\footnotetext{
A. Yikilmaz $(\bowtie)$

Department of Radiology, Gevher Nesibe Hospital, Erciyes Medical School,

Talas Street,

Kayseri 38039, Turkey

e-mail: ayikilmaz@erciyes.edu.tr

G. A. Taylor

Department of Radiology, Children's Hospital Boston, Harvard Medical School,

Boston, MA, USA
}

\section{Introduction}

Bacterial meningitis is an uncommon but serious condition in the newborn and infant child. The incidence of bacterial meningitis has shown a dramatic decline in the last 25 years in the United States [1]. But despite a number of recent advances in neonatal intensive care, rapid bacteriological assays, and potent antibiotics, neonatal bacterial meningitis remains an important cause of neurological disability worldwide [2-4]. Early diagnosis of the primary disease and its complications is essential for the prevention of neurodevelopmental sequelae. Cranial sonography is often the first imaging modality used in the evaluation of critically ill infants with suspected meningitis. Thus, familiarity with the pathophysiology and sonographic appearance of bacterial meningitis is important for the radiologist and neonatologist taking care of these patients. In this article we review and update the US features of bacterial meningitis and its complications with emphasis on the relationship between imaging findings and underlying pathological changes.

\section{Pathophysiology of meningitis}

Bacterial meningitis usually occurs as a result of bacteremia and sepsis, with initial seeding of the central nervous system via the choroid plexus. The infection then spreads into the cerebrospinal fluid (CSF) and can cause inflammation of the ventricular system (ventriculitis). Inflammation of the meninges typically follows $[2,5]$. A key feature of arachnoiditis is the presence of vasculitis, predominantly in small and medium-size veins that traverse the subarachnoid space [5]. Meningeal inflammation extends to the walls of the bridging and cortical veins to cause thrombophlebitis 
and vascular occlusion, which is associated with cortical infarcts [5, 6]. A number of bacterial virulence factors and inflammatory cytokines contribute to the inflammatory process, resulting in diffuse cerebral edema, increased intracranial pressure, and alterations of cerebral blood flow [7-9]. Lipopolysaccharides found in the bacterial cell wall can lead to a disruption in the blood-brain barrier and invasion of microorganisms into deeper cerebral structures $[10,11]$. Arachnoiditis and ventriculitis might also contribute to a more generalized encephalopathy characterized by neuronal loss, gliosis and periventricular leukomalacia [2]. Later pathological findings include diffuse cerebral cortical and white matter atrophy, hydrocephalus, which can also be seen in the early phase, multicystic encephalomalacia, porencephaly and ventricular septations $[2,3,5,12,13]$.

In the acute phase of meningitis, marked vasodilatation of cortical vessels is often present as the result of potent vasogenic effects of bacterial toxins. In later stages of the disease, there is a global reduction in cerebral blood flow attributed to impairment of cerebral autoregulation and brain edema [14].

In the newborn infant, streptococcus group B, Escherichia coli, and Listeria monocytogenes are the most commonly isolated organisms in CSF. Although other gram-negative enteric organisms such as Klebsiella species and Citrobacter species are less common, they can have far more devastating consequences [15].

\section{Sonographic features of meningitis}

Sonographic abnormalities are present in approximately $65 \%$ of infants with acute bacterial meningitis [3, 16-22]. However, the frequency of imaging abnormalities in patients with a clinical presentation complicated by persistent seizures, abnormal neurological findings and a deterioration of CSF examination within the first $48 \mathrm{~h}$ can be as high as $100 \%$ [17]. The high incidence of positive sonograms in infants with suspected complications resulted in the recommendation by some authors to use sonography only when there is a clinical suspicion of a complication [3]. Han et al. [3] found that no infant without a clinical indication of complications of meningitis had clinically significant findings on sonography. However, other authors suggest a sonographic examination should be used on every infant with or without evidence of complications on the basis of reports of a high incidence of positive findings in infants without any clinical indication of complications [17, 23, 24]. Rosenberg et al. [23] suggest an initial examination at the time of diagnosis of bacterial meningitis and a follow-up study within 1 week if the initial study demonstrates any parenchymal or ventricular abnormality.

We recommend cranial sonography as a baseline study in every infant who has an adequate size fontanel if the diagnosis of bacterial meningitis is suspected clinically. Because the major advantage of sonography is its ability to be safely repeated, a second study should be performed if any clinical deterioration occurs, such as increasing head circumference, occurrence of new neurological findings, and lack of response to therapy. However, in patients with complicated bacterial meningitis whose clinical situation is sufficiently stable to leave the nursery, MRI should be the next study of choice. In children, MRI is widely accepted for its safety and high soft-tissue resolution. It is superior to sonography in showing the existence and extension of the complications, especially in the posterior fossa. It has the further advantage of not using ionizing radiation.

It is essential to use state-of-the-art equipment with optimized settings including linear, curved and vector probes with variable megahertz in order to perform a complete evaluation of the meninges because of the often subtle sonographic changes of bacterial meningitis $[25,26]$.

\section{Meningeal and extra-axial findings}

In healthy individuals, the pia-arachnoidal membrane is seen as an echogenic line on the surface of the brain. Normal thickness of the membrane measured from the surface of a frontal gyrus (single layer) and within a sulcus (double layer) should not exceed $1.3 \mathrm{~mm}$ and $2 \mathrm{~mm}$, respectively [27]. Echogenic widening of brain sulci, or meningeal thickening, is the most common and earliest sonographic sign of meningitis, seen in $26-83 \%$ of affected patients (Fig. 1) [3, 16-20, 28]. Prominent cortical vessels can be seen within the pia-arachnoid on color Doppler sonography (Fig. 2). These findings reflect the intense inflammatory exudate that accumulates in the depths of the fissures and sulci, especially around the pial and subarachnoid vessels [5]. Despite their common occurrence, signs of meningeal inflammation are temporary and unrelated to any significant clinical or neurological outcome $[3,16,20]$.

Accumulation of extra-axial fluid might be present in 8$33 \%$ of infants with bacterial meningitis. Most commonly, these represent sterile, reactive subdural effusions that have no prognostic significance $[3,16,19,20,28]$. On sonography, they appear as hypoechoic concave fluid spaces, sometimes containing mobile echogenic debris (Fig. 3). Empyema is a very rare complication of meningitis, present in up to $1 \%$ of affected patients $[3,5,17,24]$. Although it is often difficult to differentiate a sterile effusion from an early empyema [28], an enlarging complex extra-axial fluid space is a concerning finding. Such spaces can become quite large and cause a mass effect on the adjacent brain parenchyma [29] (Fig. 4). Clinical findings including persistent fever, new focal neurological signs or seizures are not sufficient for suspicion of subdural empyema because they are not specific 

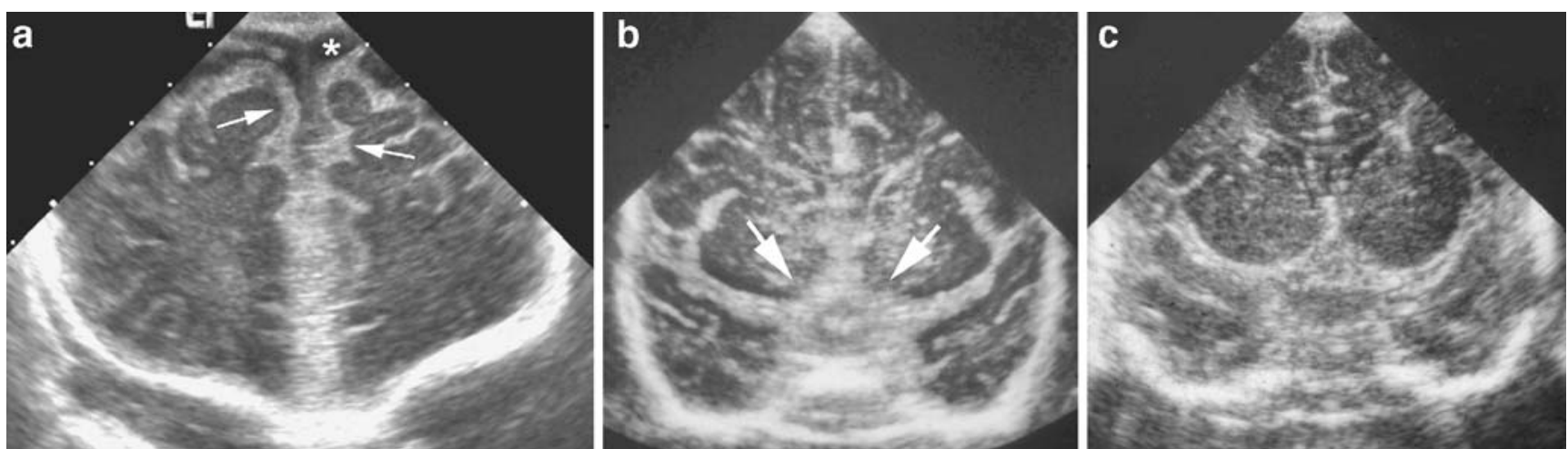

Fig. 1 Thickened meninges. a Coronal sonogram through frontal lobes in an 11-week-old infant with group streptococcus group B meningitis demonstrates diffuse echogenic thickening of the leptomeninges (arrows) and prominent extra-axial fluid spaces (asterisk). b, c
Coronal sonogram on a different infant with group streptococcus group B meningitis (b) shows marked thickening of the suprasellar cisterns (arrows), compared to a normal infant (c) for the diagnosis of empyema [30]. Hence, a combination of imaging modalities and clinical evaluation is necessary for the early diagnosis of subdural empyema. The final diagnosis is based on the analysis of the subdural effusion [31].

The distinction between subarachnoid and subdural location of extra-axial fluid is important in the management of infants with meningitis. Isolated subarachnoid fluid spaces up to $3.3 \mathrm{~mm}$ are considered incidental findings of no clinical importance in meningitic infants, whereas neurosurgical evacuation is the therapy of choice for infected subdural effusions (empyema) [25, 32]. Early detection with frequent sonographic monitoring of subdural effusions might lessen the neurological sequelae in infantile and neonatal purulent meningitis [33]. Color Doppler sonography can be very helpful in differentiating benign enlargement of subarachnoid spaces from subdural effu-

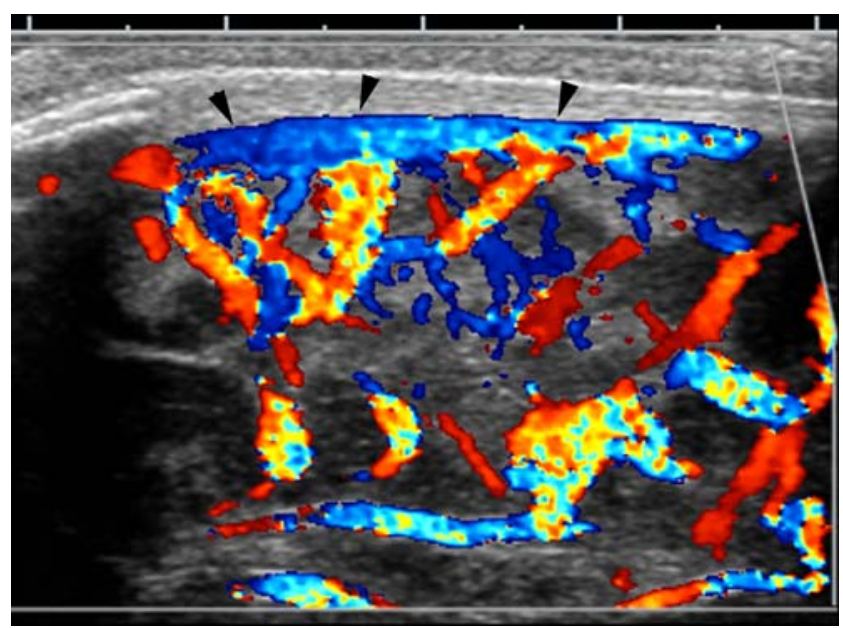

Fig. 2 Vasodilatation of pial vessels. Angled sagittal midline color Doppler sonogram in a 3-week-old infant with streptococcus group B meningitis shows prominent vascularity along the surface of the brain parenchyma and a patent superior sagittal sinus (arrowheads) sions $[34,35]$. When subarachnoid fluid is present cortical vessels on the brain surface are surrounded by fluid, whereas fluid in the subdural space compresses the cortical vessels along the surface of the brain (Fig. 5).

\section{Intraventricular findings}

The most common sonographic signs of ventriculitis include an irregular and echogenic ependyma, the presence of intraventricular debris and stranding, often associated with ventricular dilatation. Debris in the ventricles can be caused by any infecting organism; however, it is most frequently seen with $E$. coli meningitis [3,36]. The amount and coarseness of intraventricular debris can vary considerably (Fig. 6) and reflects the extent of ventriculitis. Sonographic resolution of intraventricular debris reflects the efficacy of antibiotic treatment [37]. Inflammation within the ventricles can cause intraventricular adhesions and formation of septae as a more chronic complication of meningitis in about $10 \%$ of patients [21, 28, 38]. These adhesions can cause compartmentalization in the ventricles, leading to intraventricular cyst formation (Fig. 7). The identification of the ventricular septations is very important in planning for appropriate shunt placement. Sonography is the study of choice for the demonstration of these septations, often demonstrating them better than CT [38].

Although histopathological studies have shown exudative inflammation of the choroid plexus (plexitis) and of the ependymal lining (ventriculitis) in up to $93 \%$ of those autopsied $[5,13]$, only those with more severe involvement exhibit abnormal findings on cranial sonography [3, 16, 20, 28]. By US examination, the choroid plexus can appear more echogenic and its contours irregular and poorly defined [16, $28,38,39]$. The ependyma can have a thick, irregular and echogenic appearance, as well [20, 28, 37-39]. 
Fig. 3 Subdural effusion. a Coronal midline sonogram in a 3-week-old infant with streptococcus group B meningitis shows echogenic debris within subdural fluid. b Axial diffusion-weighted MR image shows markedly hyperintense signal in the extra-axial fluid consistent with restricted diffusion caused by meningeal edema or pus
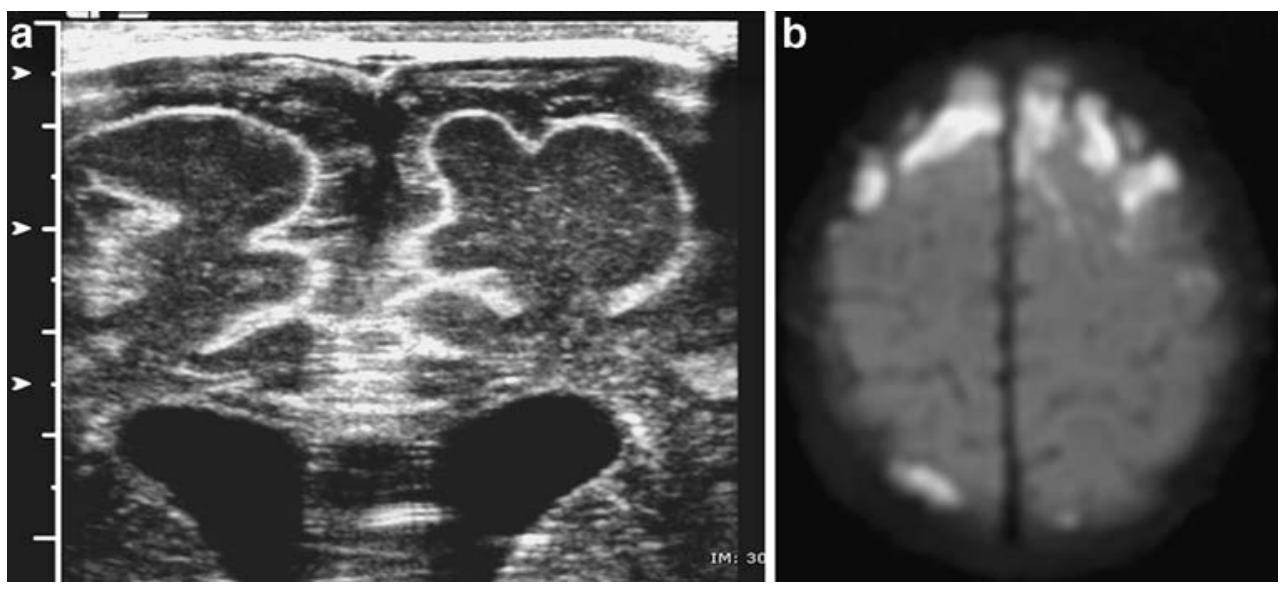

\section{Parenchymal findings}

Abnormal parenchymal echogenicity

Areas of abnormal brain echogenicity have been reported in $12 \%$ to $65 \%$ of infants with bacterial meningitis $[3,20,28]$. Lesions can be focal or diffuse and can represent parenchymal involvement by cerebritis, infarction, second-
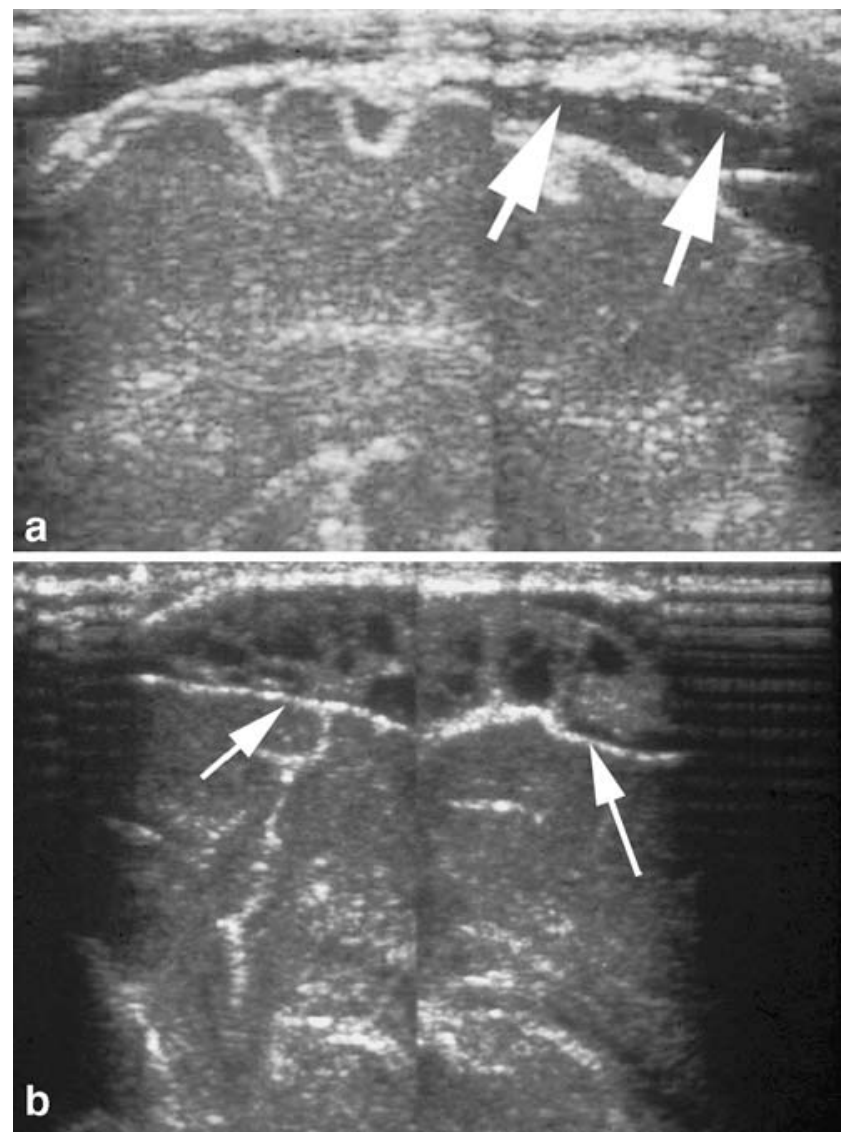

Fig. 4 Subdural empyema. a Angled sagittal sonogram in a 1-weekold infant with $E$. coli meningitis shows thickened septations in the subdural space (arrows). b Repeated sonogram at 2 weeks of age shows a complex heterogeneous collection consistent with focal empyema (arrows). Needle aspiration confirmed the presence of pus ary hemorrhage or early abscess $[3,17,40]$. The presence and size of parenchymal lesions are associated with significant neurological sequelae and are indicators of a poor prognosis [3].

One of the most devastating complications of bacterial meningitis is abscess formation. It has been reported with a frequency of between $1 \%$ and $18 \%$ in newborns with meningitis $[2,3,16,21,28]$. Mortality rates are significant (15-75\%), and up to $66 \%$ of survivors develop neurological sequelae $[41,42]$.

Most cerebral abscesses are caused by a member of the Enterobacteriaceae family (Citrobacter and Enterobacter species) [43, 44]. Citrobacter koseri (formerly C. diversus) is the main causative agent leading to abscess formation in the brain $[43,45]$. Up to $77 \%$ of infected patients develop an intracerebral abscess. The major pathological feature of Citrobacter meningitis is vasculitis followed by infarction, with necrosis and liquefaction of large portions of the white

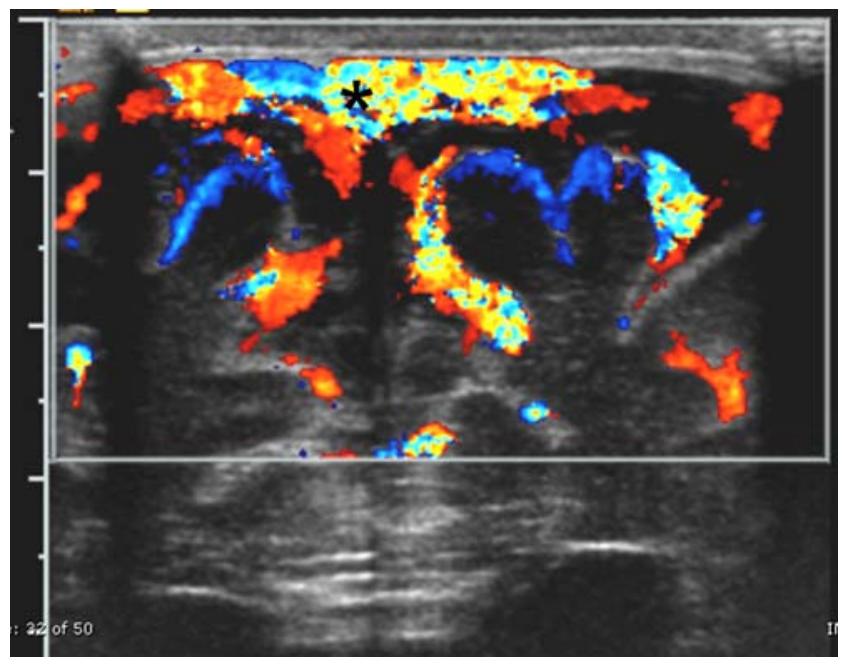

Fig. 5 Subdural fluid. Midline coronal color Doppler sonogram in an 11-week-old infant with group streptococcus group B meningitis shows cortical vessels along the surface of the left hemisphere (blue vessels). Vasculature is located in the pia-arachnoid space and is not surrounded by fluid. This finding strongly suggests that fluid is in the subdural space. Note the superior sagittal sinus (asterisk) 
Fig. 6 Ventriculitis. a-c Coronal (a), left sagittal (b), and mastoid sonograms (c) obtained in a 12-day-old premature infant with $E$. coli meningitis show extensive septations and echogenic debris clots filling the lateral, third and fourth ventricles. Note the echogenic thickening of edematous ependyma (arrows). d Repeat coronal sonogram at 19 days of age shows a decrease in size and heterogeneity of the intraventricular debris. Note progression of ventricular dilatation
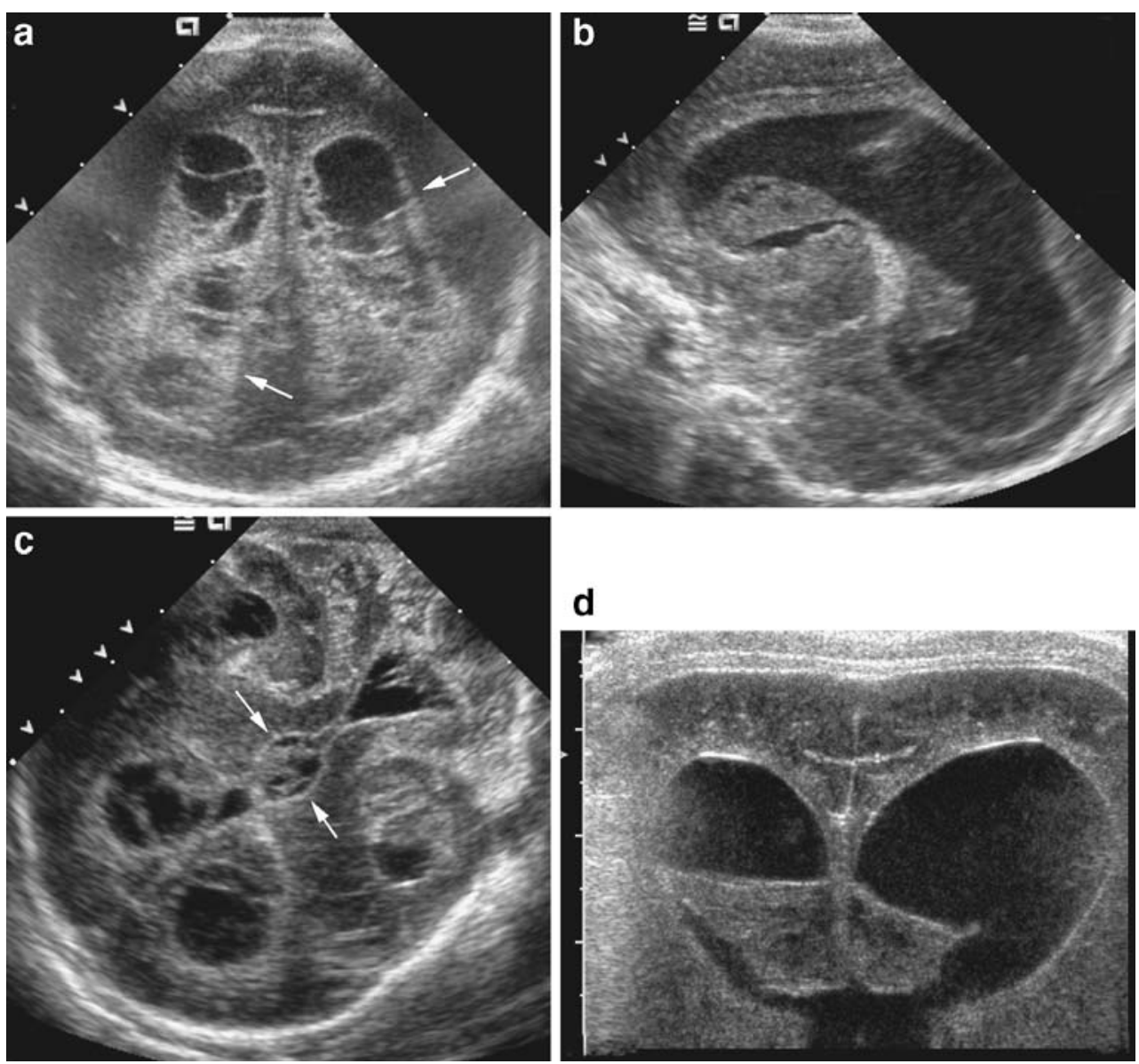

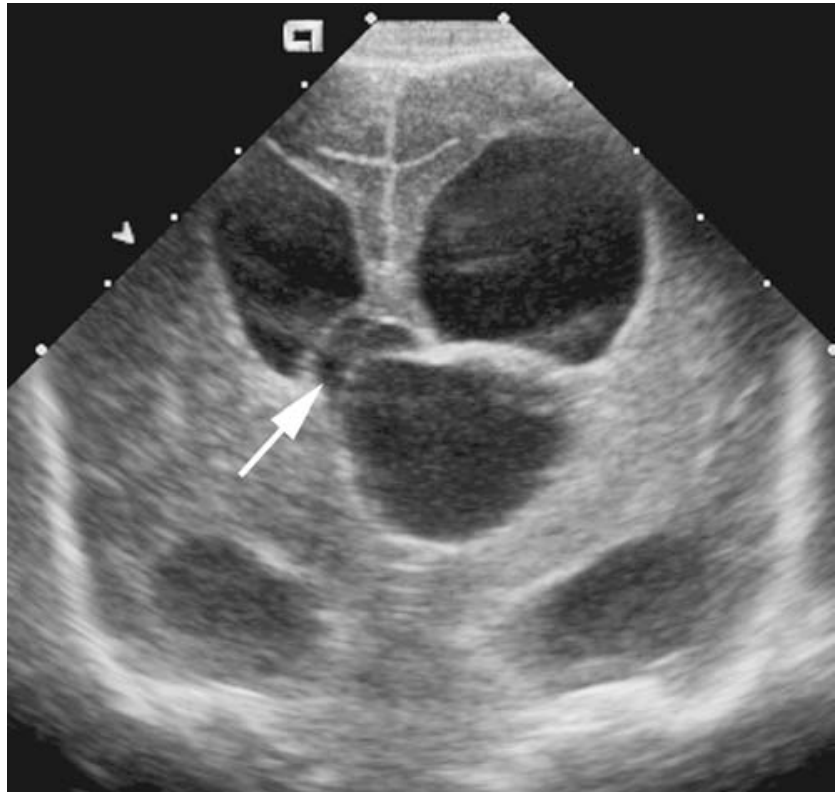

Fig. 7 Cyst formation. Coronal image obtained in a 5-week-old infant with $E$. coli meningitis shows a midline cyst displacing the third ventricle (arrow) superiorly and to the right matter of the hemispheres [45, 46]. Hemorrhagic necrosis and liquefaction can also occur [43, 46]. Surgical drainage of these lesions is not recommended to avoid further damage to surrounding brain parenchyma [46].

The sonographic appearance of abscess varies with the stage of the infection. During the initial stage of cerebritis, sonography might only show a poorly marginated area of increased echogenicity with increased vascularity using color or power Doppler [2] (Fig. 8). As the abscess matures the lesion becomes a well-circumscribed, complex solid mass with highly echogenic walls [3, 21]. After progression with/or without antibiotic therapy the lesions progress to cavitation with marked peripheral hyperemia [16, 21, 47, 48]. Sonographic differentiation between hemorrhagic necrosis and abscess is not always possible, and percutaneous sampling of the intracavitary fluid might be necessary. Sonographic guidance can be useful for puncture, aspiration, and irrigation of the abscess cavity $[49,50]$.

\section{Brain edema}

In the acute stage of meningitis, both intra- and extracellular edema can occur. As a result, the lateral ventricles as well as the other cisternal structures can be compressed or 

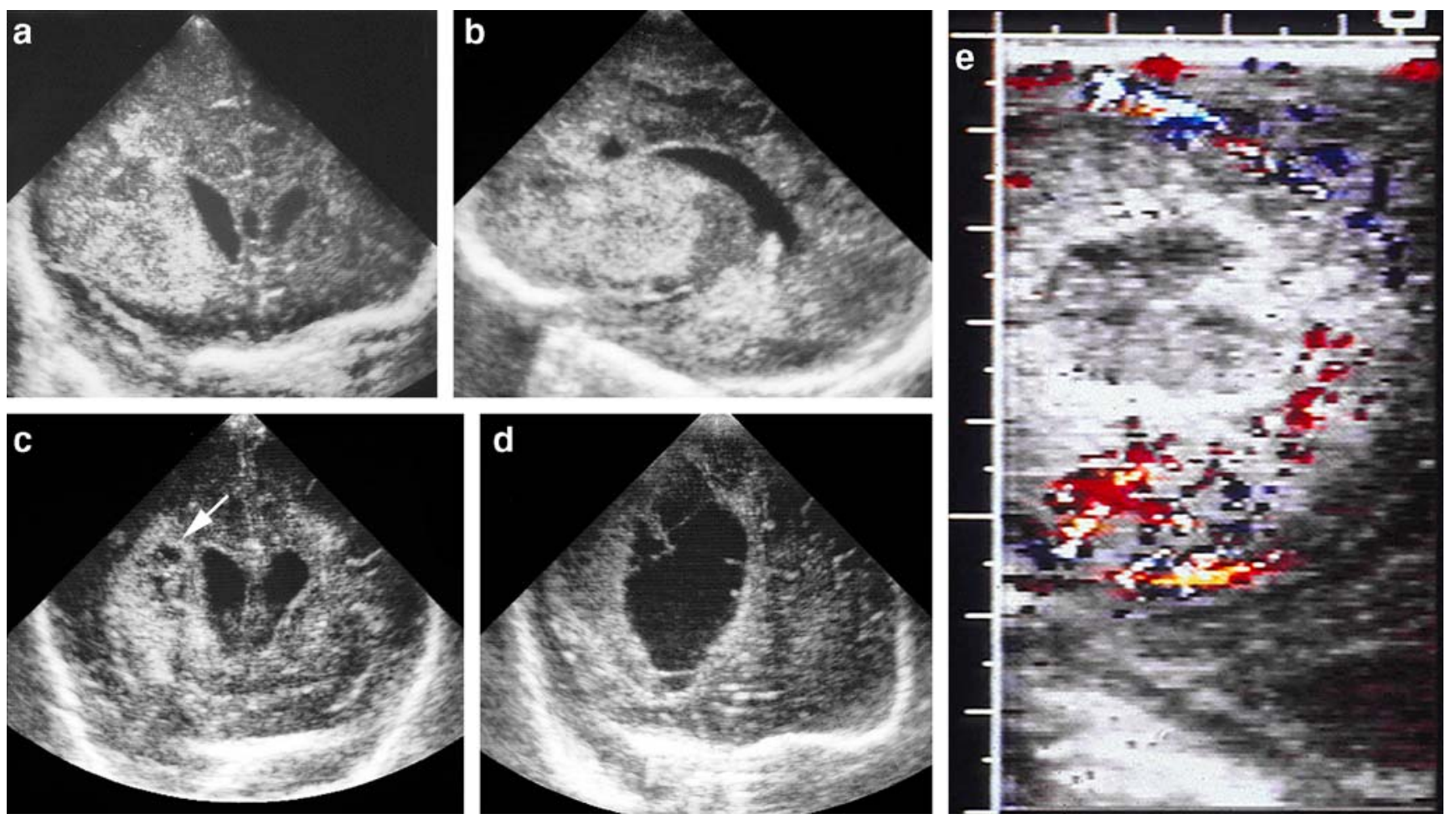

Fig. 8 Liquefactive cerebritis. a, b Coronal (a) and sagittal right (b) sonograms through the frontal lobes in a full-term infant with Citrobacter meningitis show extensive echogenic cerebritis involving the right frontal lobe and basal ganglia. $\mathbf{c}$ Repeated sonogram 5 days later shows early liquefaction of the frontal lobe (arrow). d, e Coronal

obliterated [5]. The range of ventricular size is quite wide, from mild compression to complete sonographic obliteration, the latter being a poor prognostic factor [28, 51]. On sonography, there might be a diffuse or heterogeneous

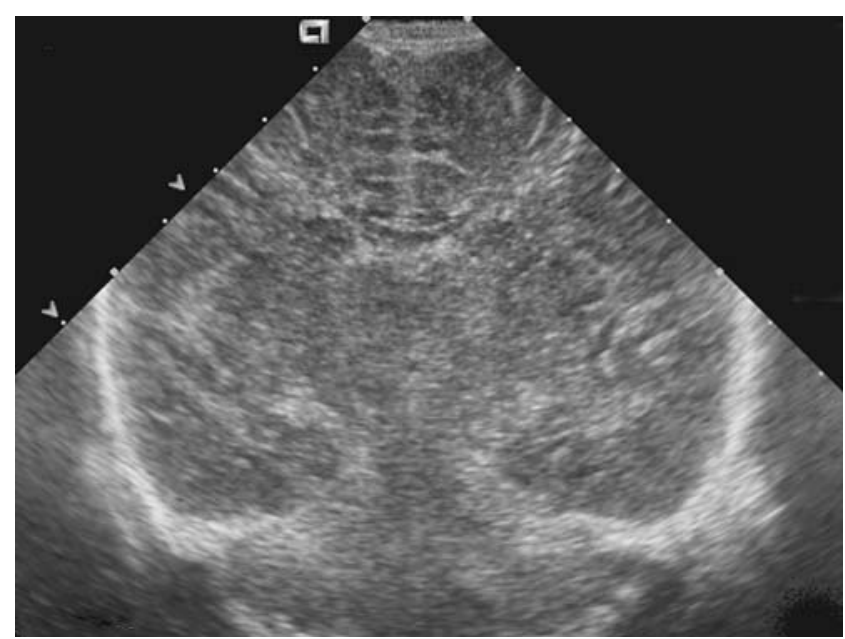

Fig. 9 Brain edema. Coronal sonogram in a 7-day-old infant with group B streptococcus meningitis shows generalized edema with compression of lateral ventricles and sulci and diffuse increased heterogeneity of the cerebral hemispheres sonogram obtained after 7 days (d) demonstrates complete liquefaction of involved brain and surrounding hyperemia on color Doppler sonography (e). Needle aspiration revealed necrotic tissue with no organism

increase in the echogenicity of the brain with effacement of the sulci and gyri $[20,23,28,50,52]$ (Fig. 9). Increased intracranial pressure is associated with increased pulsatility of arterial flow, reflected in elevated resistive index (RI) values on pulsed Doppler sonography. Other causes of elevated pulsatility of flow include venous thrombosis (Fig. 10), large extra-axial fluid collections, and postinfectious hydrocephalus. Retrograde blood flow during diastole is an indication of markedly altered intracranial compliance [53-57]. When equivalent antegrade and retrograde blood flow is present during numerous cardiac cycles, this might be an indication of nonviable brain blood flow $[35,58]$.

Diffuse cerebral atrophy, multicystic encephalopathy, and porencephaly might be seen as the end-stage of complications of bacterial meningitis.

\section{Hydrocephalus}

Ventricular dilatation is present in 14-65\% of infants with bacterial meningitis and can occur in either the acute or the chronic phase of the disease [16-21, 28]. The level of obstruction to CSF flow is usually outside the ventricular system but can occur within the narrowest portions of the 
ventricles as a result of ependymitis and secondary adhesion. Common locations for intraventricular obstruction include the aqueduct of Sylvius and the exit foramina of the fourth ventricle [16].
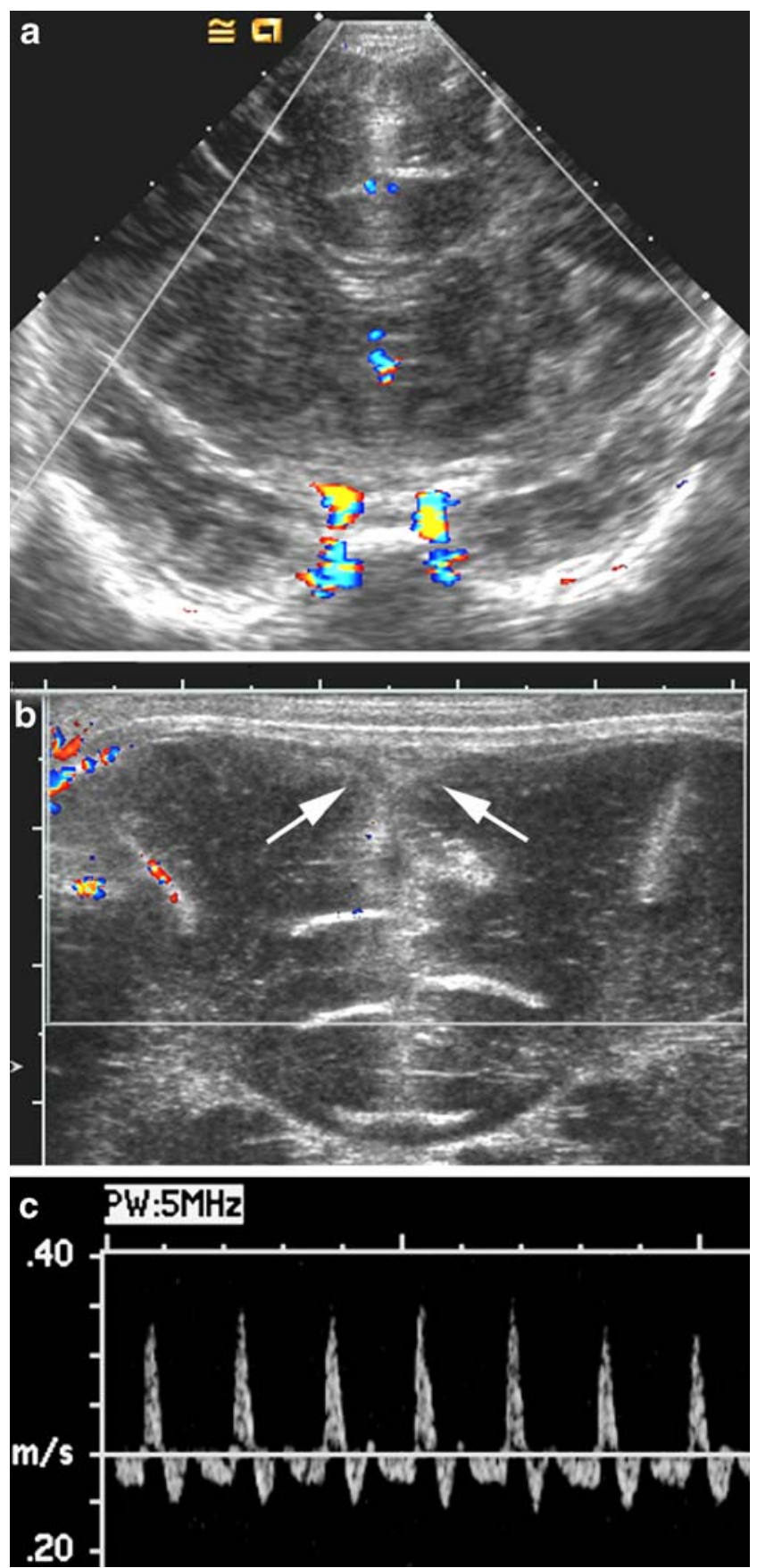

Fig. 10 Sagittal sinus thrombosis, nonviable blood flow. a Coronal color Doppler image an 18-day-old infant with group B streptococcus meningitis shows flow limited to internal carotid arteries at the base of the brain. b On the magnified coronal color Doppler image no flow is identified in the superficial sagittal sinus (arrows), and the thrombosis of the sinus was also confirmed on sagittal scans using high-sensitivity Doppler settings (not shown). c Duplex Doppler waveform of the anterior cerebral artery without fontanel compression shows reversal of flow during the entire diastolic phase
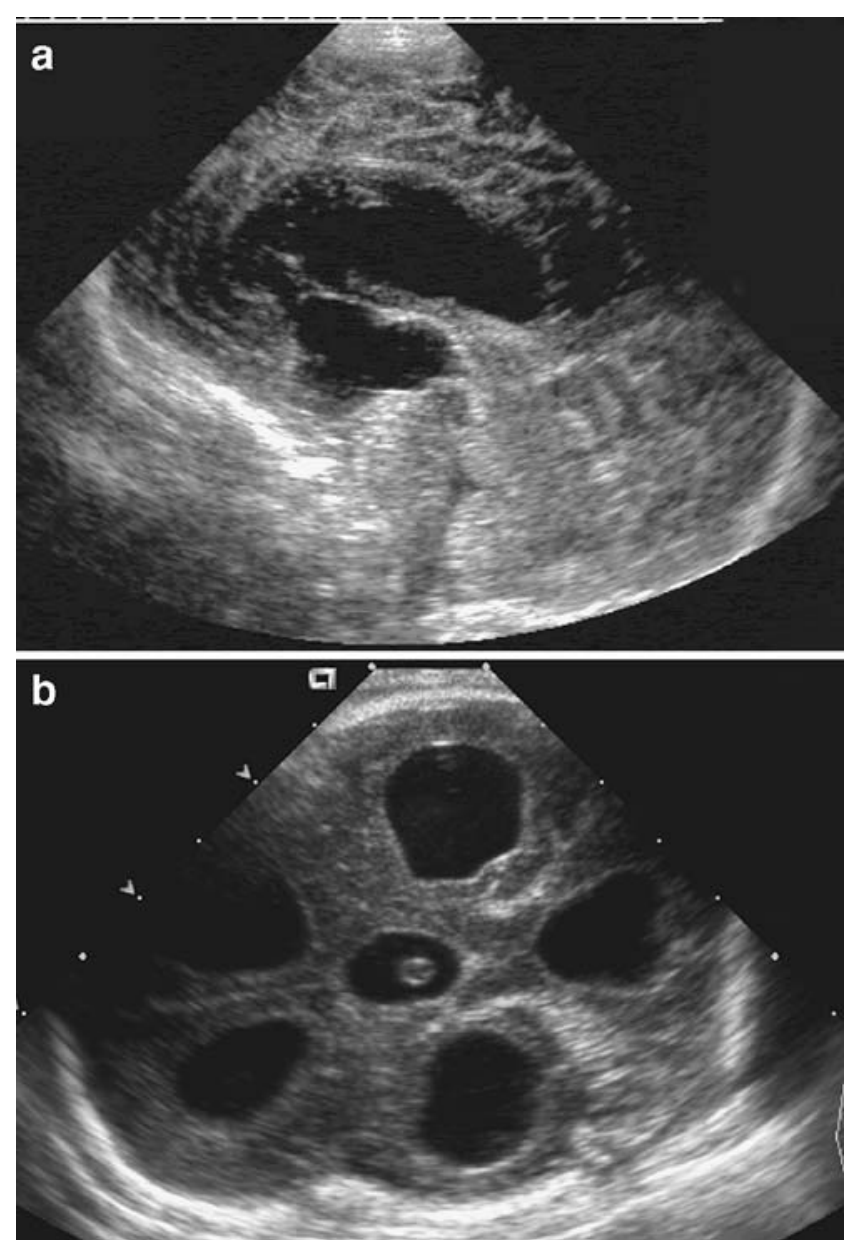

Fig. 11 Postinfectious hydrocephalus. a Midline sagittal sonogram in an infant with aqueductal stenosis following group B streptococcus meningitis shows dilatation of the lateral and third ventricles; the fourth ventricle is normal. b Mastoid fontanel view of another infant with group B streptococcus meningitis shows markedly dilated lateral, third, and fourth ventricles secondary to obstruction of the fourth ventricle outlet foramina. Note the echogenic particle in the third ventricle, which could be debris or a clot

Sonography can play an important role in the detection of hydrocephalus, in the determination of the level of obstruction, and in the evaluation of intracranial compliance. In aqueduct stenosis the lateral and third ventricles are disproportionately dilated, the aqueduct is thickened and echogenic and the fourth ventricle is of normal size (Fig. 11). Detection of CSF flow through the aqueduct of Sylvius is possible by imaging the aqueduct using the mastoid fontanel view. Using power Doppler sonography, the anterior fontanel is compressed and quickly released. Particulate debris within the CSF allows power Doppler signal to be detected when CSF flows in a retrograde fashion through a patent aqueduct into the third ventricle [59].

Pulsed Doppler interrogation of the anterior cerebral artery before and after compression of the anterior fontanel can be a useful adjunct in the serial monitoring of infants with postinfectious hydrocephalus [53, 54, 57]. Increasing 
response to fontanel compression as manifested by increasing changes in arterial RI can be an indication for shunt placement in infants with rapidly progressive hydrocephalus.

Sonographic evaluation of the thoracolumbar spine in infants with meningitis might reveal the presence of echogenic debris within the spinal subarachnoid space. This finding has been associated with a higher risk of progressive hydrocephalus [60].

\section{Conclusion}

Cranial sonography continues to be an excellent front-line imaging modality in the initial diagnosis and monitoring of infants with acute bacterial meningitis and its potential complications. Its utility is enhanced by the use of alternative scanning approaches and Doppler techniques for identification of ventriculitis, extra-axial fluid collections, and hemodynamic alterations. Spinal sonography might also play a role in assessing the risk of progressive hydrocephalus.

\section{References}

1. Schuchat A, Robinson K, Wenger JD et al (1997) Bacterial meningitis in the United States in 1995. Active surveillance team. N Engl J Med 337:970-976

2. Volpe JJ (2001) Bacterial and fungal intracranial infections. In: Volpe JJ (ed) Neurology of the newborn. Saunders, Philadelphia, pp 774-810

3. Han BK, Babcock DS, McAdams L (1985) Bacterial meningitis in infants: sonographic findings. Radiology 154:645-650

4. Edwards MK, Brown DL, Muller J et al (1981) Cribside neurosonography: real-time sonography for intracranial investigation of the neonate. AJR 136:271-275

5. Berman PH, Banker BQ (1966) Neonatal meningitis. A clinical and pathological study of 29 cases. Pediatrics 38:6-24

6. DiNubile MJ, Boom WH, Southwick FS (1990) Septic cortical thrombophlebitis. J Infect Dis 161:1216-1220

7. Tunkel AR, Scheld WM (1993) Pathogenesis and pathophysiology of bacterial meningitis. Clin Microbiol Rev 6:118-136

8. Tunkel AR, Scheld WM (1993) Pathogenesis and pathophysiology of bacterial meningitis. Annu Rev Med 44:103-120

9. Pfister HW, Fontana A, Tauber MG et al (1994) Mechanisms of brain injury in bacterial meningitis: workshop summary. Clin Infect Dis 19:463-479

10. Tunkel AR, Scheld WM (1989) Alterations of the blood-brain barrier in bacterial meningitis: in vivo and in vitro models. Pediatr Infect Dis J 8:911-913

11. Tunkel AR, Rosser SW, Hansen EJ et al (1991) Blood-brain barrier alterations in bacterial meningitis: development of an in vitro model and observations on the effects of lipopolysaccharide. In Vitro Cell Dev Biol 27:113-120

12. Kalsbeck JE, DeSousa AL, Kleiman MB et al (1980) Compartmentalization of the cerebral ventricles as a sequela of neonatal meningitis. J Neurosurg 52:547-552

13. Gilles FH, Jammes JL, Berenberg W (1977) Neonatal meningitis. The ventricle as a bacterial reservoir. Arch Neurol 34:560-562
14. Ashwal S, Stringer W, Tomasi L et al (1990) Cerebral blood flow and carbon dioxide reactivity in children with bacterial meningitis. J Pediatr 117:523-530

15. Tunkel AR, Hartman BJ, Kaplan SL et al (2004) Practice guidelines for the management of bacterial meningitis. Clin Infect Dis 39:1267-1284

16. Arrumugham R, Katariya S, Singhi P et al (1994) Sonography in pyogenic meningitis. Indian Pediatr 31:1329-1336

17. Mahajan R, Lodha A, Anand R et al (1995) Cranial sonography in bacterial meningitis. Indian Pediatr 32:989-993

18. Moorthy S, Jayakrishnan VK, Potti NS (1992) Sonographic findings in infantile bacterial meningitis. Indian J Radiol Imag 2:111-115

19. Kapoor R, Saha MM, Gupta NC (1989) Ultrasonic evaluation of complicated meningitis. Indian Pediatr 26:804-808

20. Raju VS, Rao MN, Rao VS (1995) Cranial sonography in pyogenic meningitis in neonates and infants. J Trop Pediatr 41:68-73

21. Edwards MK, Brown DL, Chua GT (1982) Complicated infantile meningitis: evaluation by real-time sonography. AJNR 3:431-434

22. Soni JP, Gupta BD, Soni M et al (1994) Cranial ultrasonic assessment of infants with acute bacterial meningitis. Indian Pediatr 31:13371343

23. Rosenberg HK, Levine RS, Stoltz K et al (1983) Bacterial meningitis in infants: sonographic features. AJNR 4:822-825

24. Gonsu-Fotsin J, Kago I, Dzogang MT et al (1990) Cerebral complications of purulent meningitis in children assessed by transfontanellar ultrasonography in Yaounde (Cameroon). Ann Radiol 33:195-199

25. Frankel DA, Fessell DP, Wolfson WP (1998) High-resolution sonographic determination of the normal dimensions of the intracranial extraaxial compartment in the newborn infant. $\mathrm{J}$ Ultrasound Med 17:411-415

26. Daneman A, Epelman M, Blaser S et al (2006) Imaging of the brain in full-term neonates: does sonography still play a role? Pediatr Radiol 36:636-646

27. Jequier S, Jequier JC (1999) Sonographic nomogram of the leptomeninges (pia-glial plate) and its usefulness for evaluating bacterial meningitis in infants. AJNR 20:1359-1364

28. Chowdhary V, Gulati P, Sachdev A et al (1991) Pyogenic meningitis: sonographic evaluation. Indian Pediatr 28:749-755

29. Raghav B, Goulatia RK, Gupta AK et al (1990) Giant subdural empyema in an infant. Sonographic observations. Neuroradiology $32: 154-155$

30. Syrogiannopoulos GA, Nelson JD, McCracken GH Jr (1986) Subdural collections of fluid in acute bacterial meningitis: a review of 136 cases. Pediatr Infect Dis 5:343-352

31. Chen CY, Huang CC, Chang YC et al (1998) Subdural empyema in 10 infants: US characteristics and clinical correlates. Radiology 207:609-617

32. Kastrup O, Wanke I, Maschke M (2005) Neuroimaging of infections. NeuroRx 2:324-332

33. Shen EY, Tsai CY, Wong TT (1998) Prospective neurosonographic study in infantile purulent meningitis. Zhonghua Min Guo Xiao Er Ke Yi Xue Hui Za Zhi 39:180-185

34. Chen CY, Chou TY, Zimmerman RA et al (1996) Pericerebral fluid collection: differentiation of enlarged subarachnoid spaces from subdural collections with color Doppler US. Radiology 201:389-392

35. Seibert JJ, Avva R, Hronas TN et al (1998) Use of power Doppler in pediatric neurosonography: a pictorial essay. Radiographics $18: 879-890$

36. Tatsuno M, Hasegawa M, Okuyama K (1993) Ventriculitis in infants: diagnosis by color Doppler flow imaging. Pediatr Neurol 9:127-130

37. Grant EG, Tessler F, Perrella R et al (1988) Infant cranial sonography. Radiol Clin North Am 26:1089-1110 
38. JD Reeder, RC Sanders (1983) Ventriculitis in the neonate: recognition by sonography. AJNR 4:37-41

39. Brown BS, Thorp P (1984) The ultrasonographic diagnosis of bacterial meningitis and ventriculitis in infancy: six case reports. $\mathrm{J}$ Can Assoc Radiol 35:47-51

40. Babcock DS, Han BK (1985) Sonographic recognition of gyral infarction in meningitis. AJR 144:833-836

41. Bell WE, McGuinness GA (1982) Suppurative central nervous system infections in the neonate. Semin Perinatol 6:1-24

42. Renier D, Flandin C, Hirsch E et al (1988) Brain abscesses in neonates. A study of 30 cases. J Neurosurg 69:877-882

43. Doran TI (1999) The role of Citrobacter in clinical disease of children: review. Clin Infect Dis 28:384-394

44. Levine RS, Rosenberg HK, Zimmerman RA et al (1983) Complications of Citrobacter neonatal meningitis: assessment by real-time cranial sonography correlated with CT. AJNR 4:668-671

45. Graham DR, Band JD (1981) Citrobacter diversus brain abscess and meningitis in neonates. JAMA 245:1923-1925

46. Foreman SD, Smith EE, Ryan NJ et al (1984) Neonatal Citrobacter meningitis: pathogenesis of cerebral abscess formation. Ann Neurol 16:655-659

47. Regev RH, Dolfin TZ, Zamir C (1995) Multiple brain abscesses in a premature infant: complication of Staphylococcus aureus sepsis. Acta Paediatr 84:585-587

48. Taylor GA (1994) Alterations in regional cerebral blood flow in neonatal stroke: preliminary findings with color Doppler sonography. Pediatr Radiol 24:111-115

49. Goraj B, Kopytek M (1991) Ultrasound: a method of brain abscess drainage monitoring. Eur J Radiol 12:120-123
50. Krajewski R, Stelmasiak Z (1992) Brain abscess in infants. Childs Nerv Syst 8:279-280

51. Hill A, Shackelford GD, Volpe JJ (1981) Ventriculitis with neonatal bacterial meningitis: identification by real-time ultrasound. J Pediatr 99:133-136

52. Buchan GC, Alvord EC Jr (1969) Diffuse necrosis of subcortical white matter associated with bacterial meningitis. Neurology 19:1-9

53. Taylor GA (1997) Recent advances in neonatal cranial ultrasound and Doppler techniques. Clin Perinatol 24:677-691

54. Taylor GA, Phillips MD, Ichord RN et al (1994) Intracranial compliance in infants: evaluation with Doppler US. Radiology 191:787-791

55. Taylor GA (1992) Effect of scanning pressure on intracranial hemodynamics during transfontanellar duplex US. Radiology 185:763-766

56. Taylor GA, Short BL, Walker LK et al (1990) Intracranial blood flow: quantification with duplex Doppler and color Doppler flow US. Radiology 176:231-236

57. Taylor GA, Madsen JR (1996) Neonatal hydrocephalus: hemodynamic response to fontanelle compression - correlation with intracranial pressure and need for shunt placement. Radiology 201:685-689

58. Chiu NC, Shen EY, Lee BS (1994) Reversal of diastolic cerebral blood flow in infants without brain death. Pediatr Neurol 11:337-340

59. Winkler P (1992) Colour-coded echographic flow imaging and spectral analysis of cerebrospinal fluid (CSF) in meningitis and hemorrhage. Part I. Clinical evidence. Pediatr Radiol 22:24-30

60. Rudas G, Almassy Z, Papp B et al (1998) Echodense spinal subarachnoid space in neonates with progressive ventricular dilatation: a marker of noncommunicating hydrocephalus. AJR 171:1119-1121 